\title{
Pile quality assessment by vibroacoustic method
}

\author{
Sergey Leonovich ${ }^{1}$, Nely Budrevich ${ }^{2 *}$, Ping Lyu ${ }^{3}$, Jijun $\mathrm{Miao}^{3}$ \\ ${ }^{1}$ Bialystok University of Technology, 15-351, ul. Wiejska 45 A, Bialystok, Poland \\ ${ }^{2}$ Belarusian National Technical University Minsk, Republic of Belarus \\ ${ }^{3}$ School of Civil Engineering, Qingdao University of Technology (Qingdao, China)
}

\begin{abstract}
In recent years, there has been a steady growth in industrial and civil construction, especially in large cities. Construction is often carried out in increasingly difficult geotechnical and hydrogeological conditions. This contributes to the emergence of new production technologies and diagnostic methods. The use of non-destructive testing methods allows you to quickly obtain information about various characteristics of an object without disrupting the process of its operation. This is especially true for hidden work, since access to the research object is practically closed, and its opening may entail undesirable consequences for the operation of the entire structure.
\end{abstract}

Keywords: vibroacoustic method, pile field, non-destructive methods, Impact echo method, acoustic contrl.

\section{Introduction}

When inspecting piles, the most productive and easy-to-use method is the surface acoustic method, known in foreign literature as the Impact echo method (IEM). The IEM method consists in shock excitation of an elastic wave of the acoustic frequency range in the inspected pile and registration of echo signals.

The surface acoustic method has been used for pile diagnostics for over 40 years. During this time, extensive experience in pile inspection has been accumulated. In the simplest case (a pile without defects or discontinuities), the IEM data obtained under the conditions of the long wavelength limit shows only a forward signal and a pulse reflected from the end of the pile. This method is the most productive and easiest to use. It is advisable to use it in cases where there is free access to the pile head and it is necessary to carry out prompt diagnostics of a sufficiently large number of piles [1-8].

Basically, these experimental studies are devoted to the determination of the mechanical characteristics of the material by observing the features of wave propagation on samples in the soil, and do not touch on the range of issues related to the interaction of the rod. Therefore, within the framework of this work, a study was carried out of the phenomena observed during the inspection of piles, on rods in the form of driven and bored piles [9-10]. 


\section{Research program}

In the course of the experiment, to determine the lengths, two types of piles were studied driven and bored (bored). Pile length measuring device - СПЕКТР 3.

\section{Experimental results}

To ensure the reliability of the results obtained, before driving and shearing off the head after failure when driving driven piles (Fig. 1,2), their length was measured with a tape measure and amounted to $8 \mathrm{~m}$.

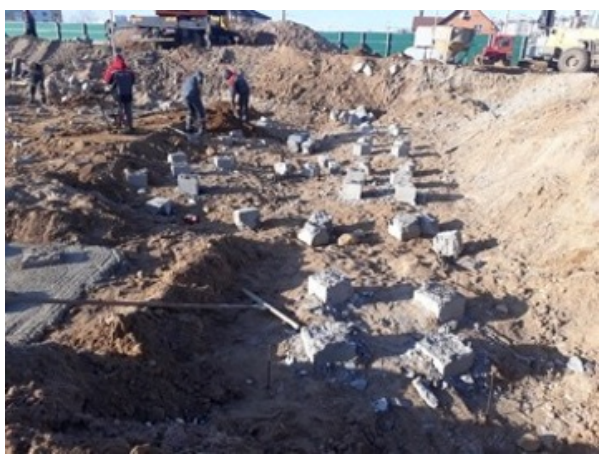

$a$

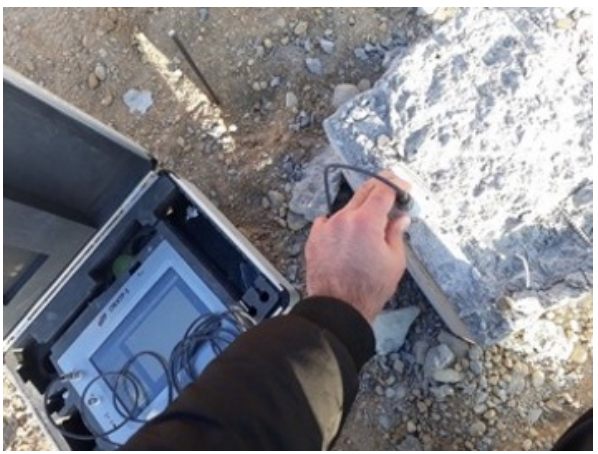

C

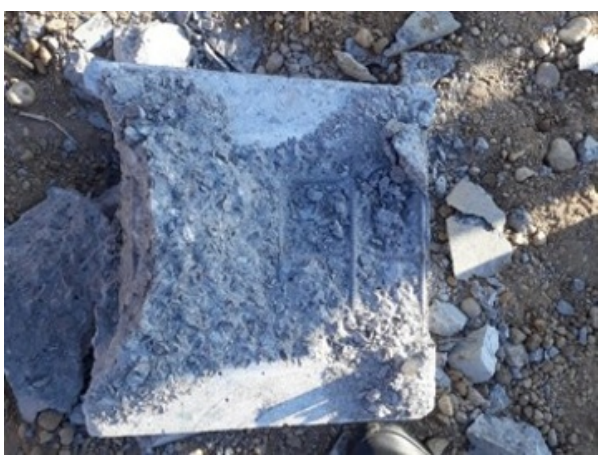

$b$

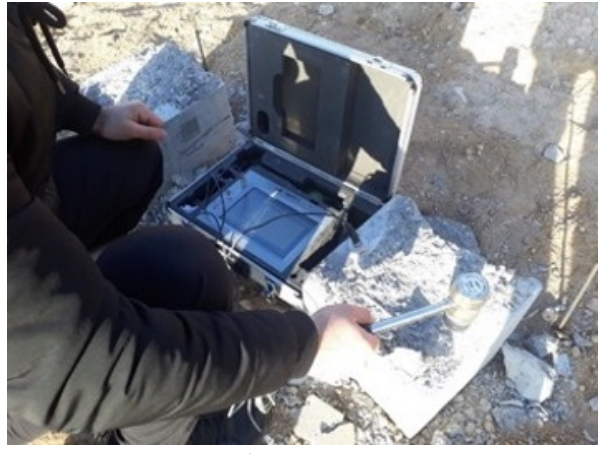

$d$

Fig. 1. Measurement process (driven piles): $a$ - pile field; $b$ - pile surface; $c$ - sensor installation; $d$ blow produc 


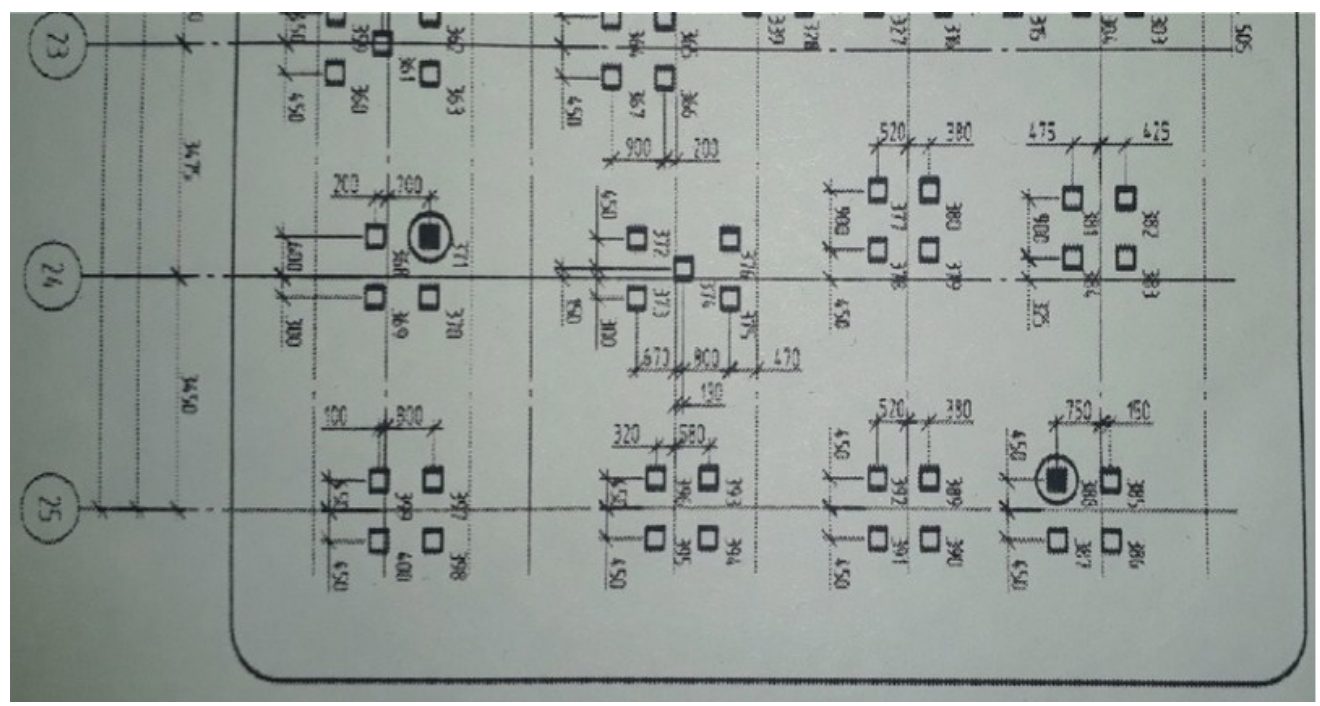

Fig. 2. Layout of driven piles

Before measuring the length of the bored piles, the design and as-built documentation was studied. The design length of the piles should be $9 \mathrm{~m}$.

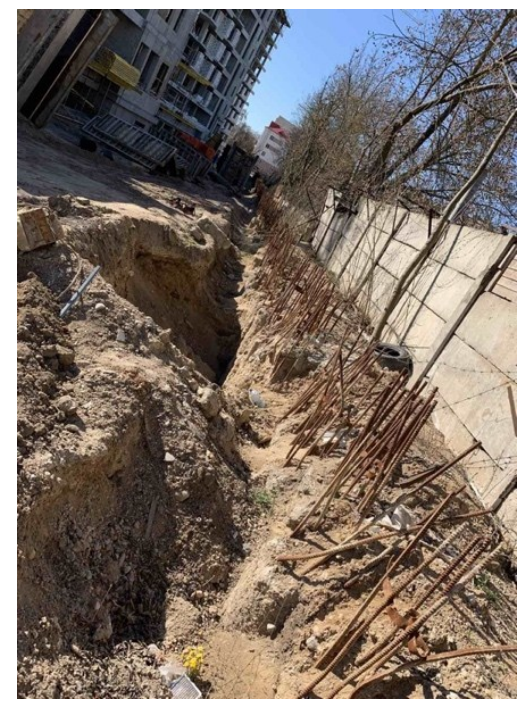

$a$

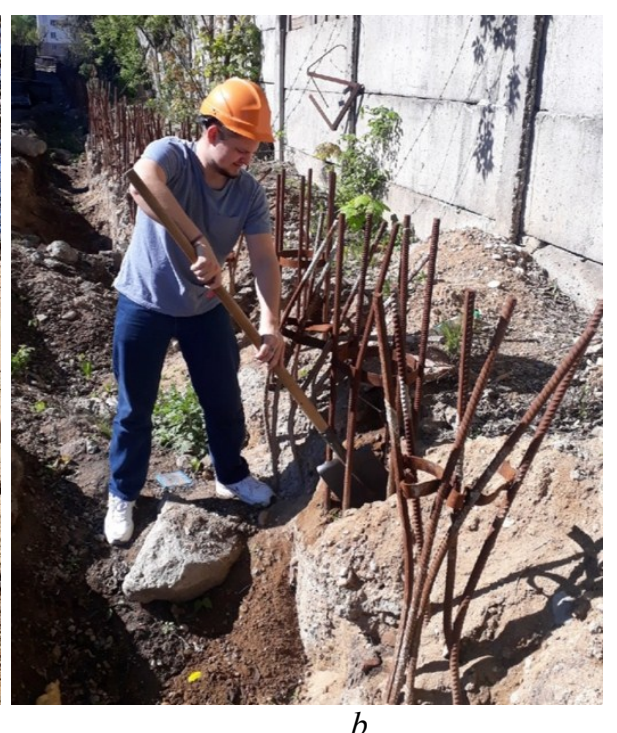

$b$ 

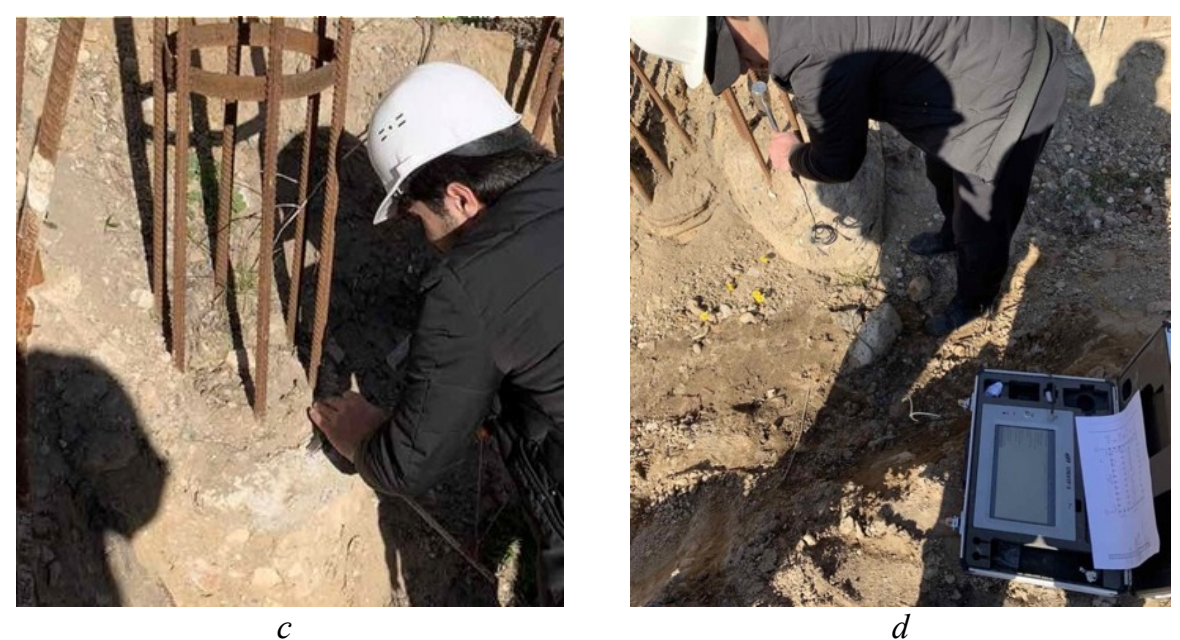

Fig. 3. Measurement process (bored piles): $a$ - pile field; $b$ - pile surface cleaning process; $c$ - leveling the surface of bored piles; $d$-measurement process
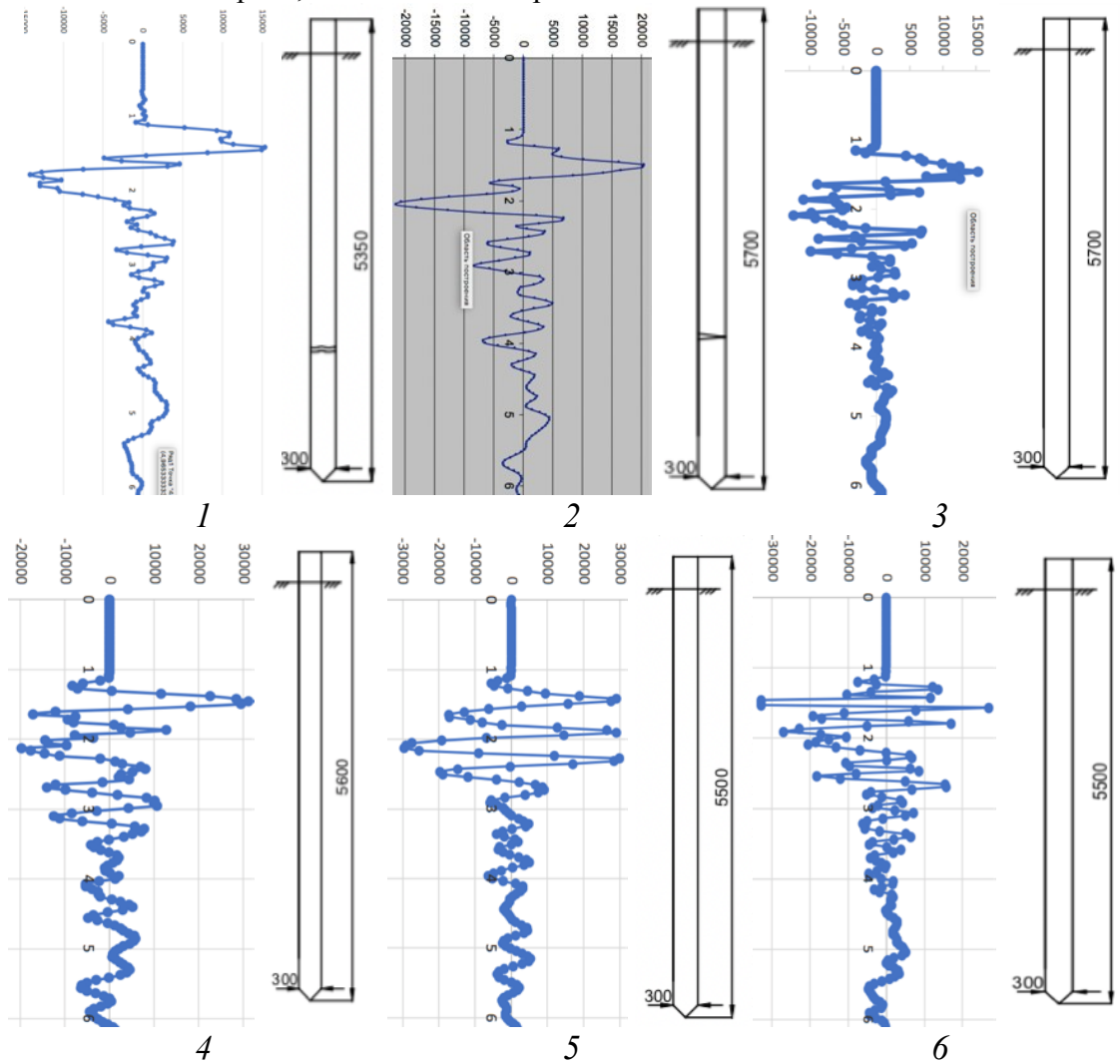

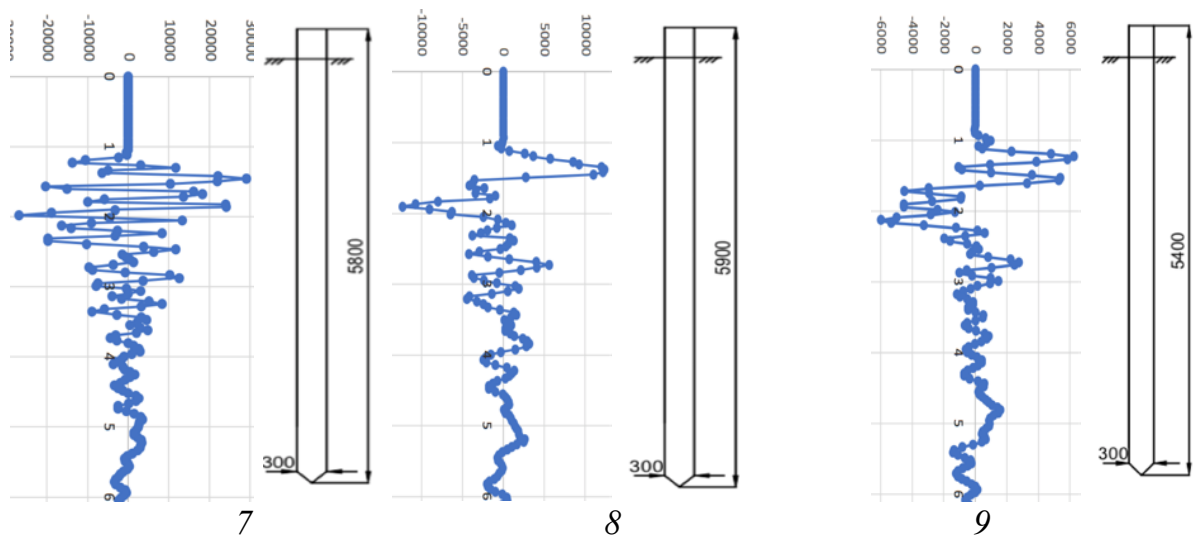

Fig. 4. Results of measuring the length of driven piles by the IEM method

As can be seen in Figure 4, according to balanced reflectograms obtained during the study of driven piles, the average length is in the range of $5.3 \ldots 5.9 \mathrm{~m}$.
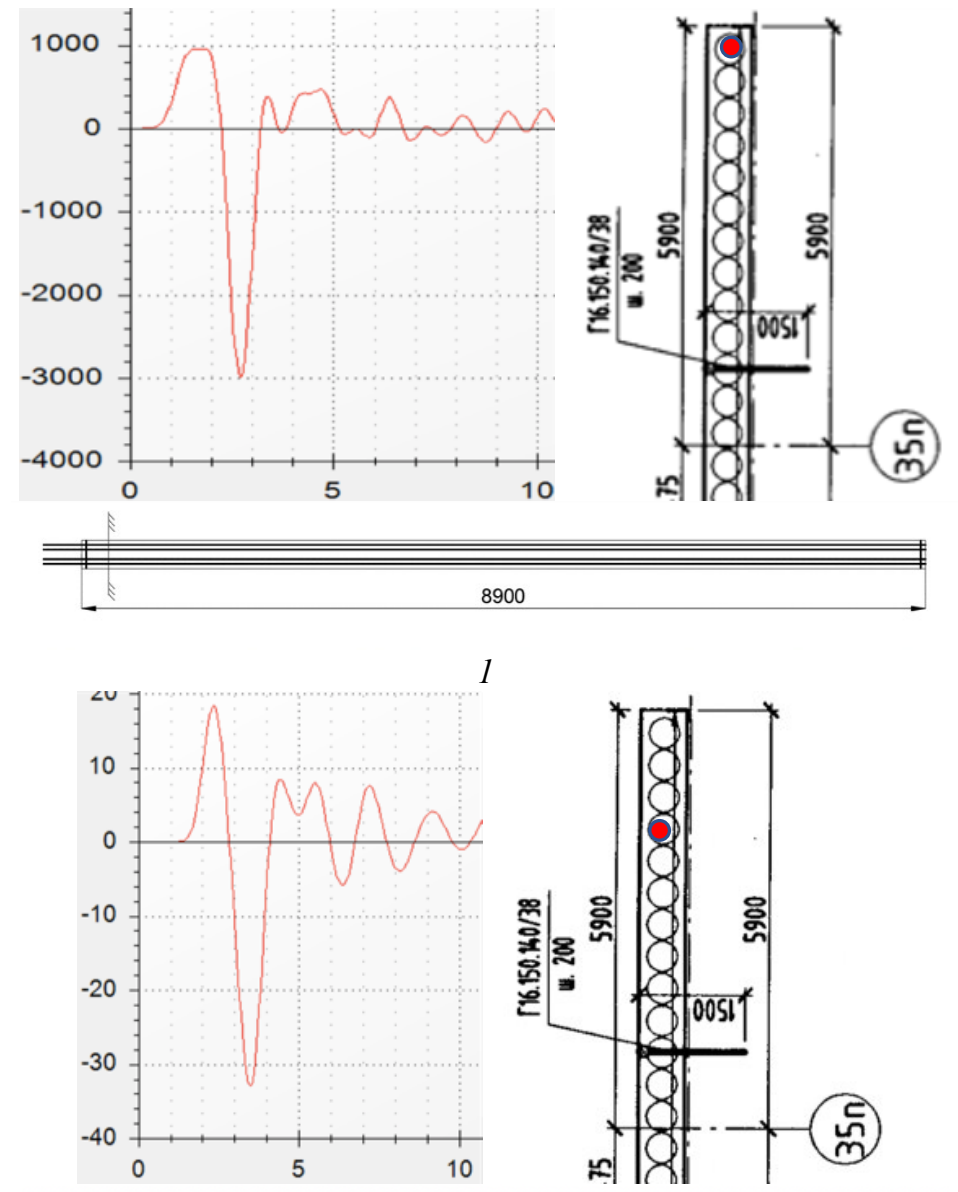

9100 

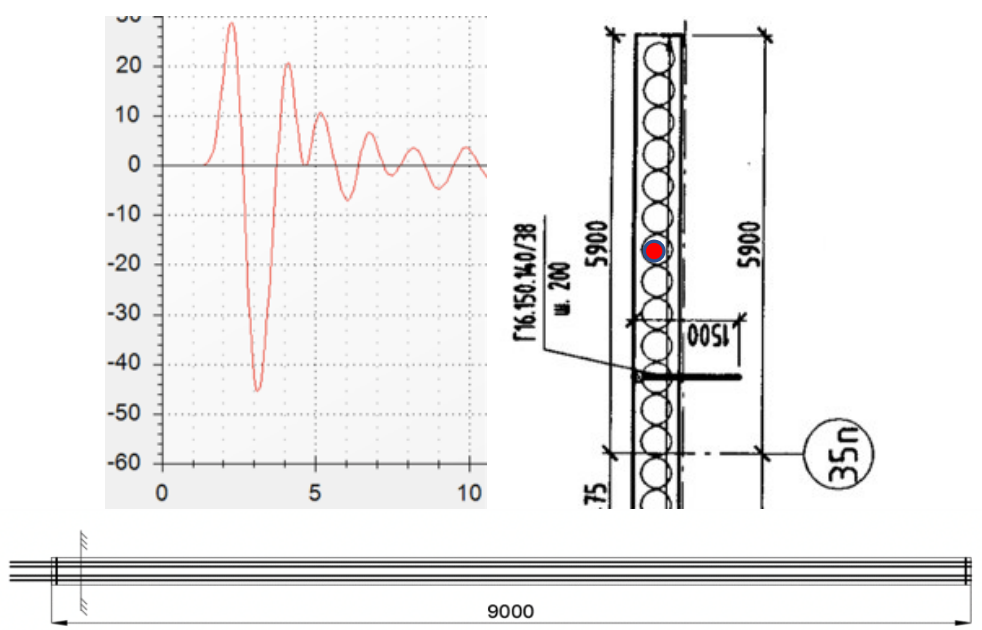

3
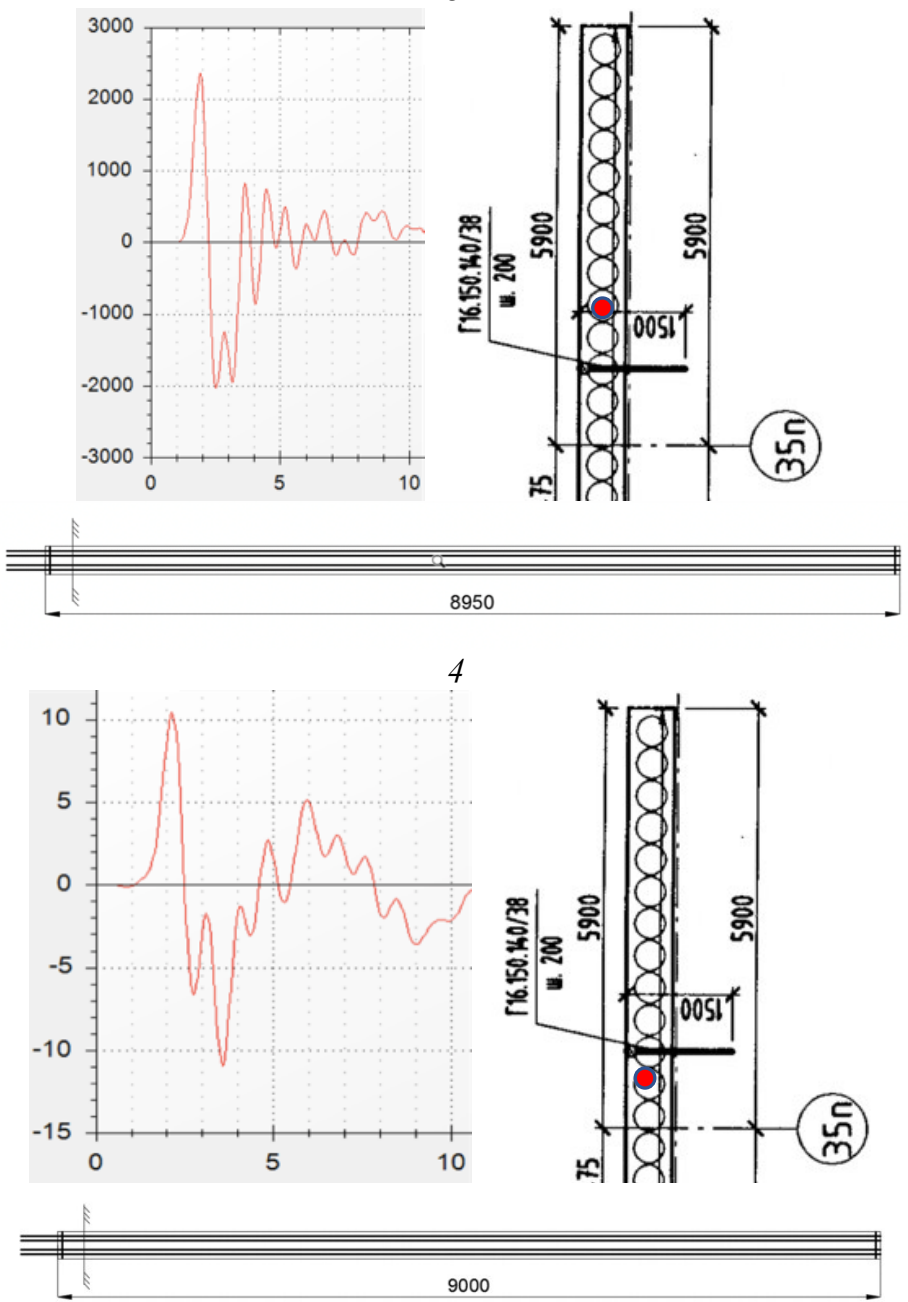


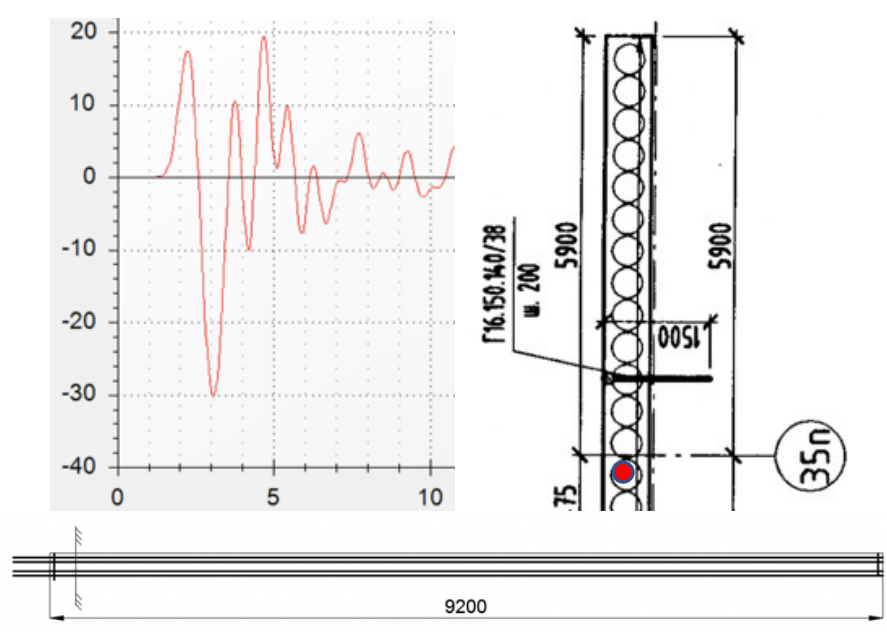

6

Fig. 5. Results of measuring the length of bored piles by the IEM method

As can be seen in Figure 5, according to the balanced reflectograms obtained during the study of bored piles, the average length is in the range of $8.9 \ldots 9.2 \mathrm{~m}$.

\section{Conclusion}

Numerous field measurements were carried out on piles [11]. The main purpose of the research was to study the records of acoustic vibrations of piles from the position of field control to assess the possibility of separating the effects associated with the propagation of a plane wave (the pile itself) and the influence of the enclosing soil, and expanding the range of problems solved by the acoustic method.

Based on the results of the conducted field experiments, the following conclusions can be drawn:

1. Controlling the acoustic field allows you to meet or not to fulfill the conditions of the long-wavelength limit. This makes it possible to study only the pile itself or the additional enclosing environment.

2. In order to distinguish between reflections associated with the pile itself and with the enclosing soil, at each measurement it is necessary to control the vibration spectrum, since the fulfillment or non-fulfillment of the conditions of the long-wave limit depends on the frequency composition with which it was possible to excite the fluctuations in this measurement.

3. If the conditions of the long-wavelength limit are not met, the registration of reflections from the boundaries in the host environment allows solving a number of additional tasks, for example, determining the depth of pile burial into the reference horizon, tracking the groundwater level, determining the depth of an artificial embankment, monitoring the quality of filling pipe piles, etc.

4. $f$ there is no data on the core velocity of the longitudinal wave, the technique of different-frequency excitation allows its estimation by observing reflections from boundaries with a known position in depth.

5. In the case of working on real piles, the concept of a "long" rod should have a broader meaning than follows from the theoretical premises. A rod can be considered "long" if the length is more than ten times the radius of the rod and at least 1 or 2 wavelengths fit in the length. 


\section{References}

1. D.Yu. Snezhkov, S.N. Leonovich. Monitoring of erected and operated reinforced concrete structures by non-destructive methods (Minsk, BNTU, 2016)

2. Samokrutov A.A., Kozlov V.N., Shevaldykin V.G., Meleshko I.A. Ultrasonic defectoscopy of concrete by means of pulse- echo technique. 8th European conference for Non-Destructive Tensing (2002)

3. M.Sansalone, J. Carino, "Impact-Echo: A Method for Flaw Detection in Concrete Using Transient Stress Waves", Report NBSIR 86-3452, National Bureau of Standards, U.S. Department of Commerce (1986)

4. K. Nagrodzka-Godycka. Badanie wlasciwosci betonu I zelbetu w warunkach laboratoryjnich. Arcady (1999)

5. S.N. Leonovich, D.Yu. Snezhkov. Non-destructive control of strength of maintained reinforced-concrete structures "Durability design and fracture mechanics of concrete structures". Internatuonal Conference (2003)

6. Christian U. Grosse, Hans W. Reinhart, Ralf Beutel «Impact- Echo measurement on fresh and hardening concrete». Institute of Construction Materials (2003)

7. T.V. Fursa. Non-destructive electromagnetic method of flaw detection of products made of dielectric materials. - Defectoscopy 10, pp. 27-32 (2003)

8. D.Yu. Snezhkov. Improvement of hardware for acoustic control of elastic-deformative characteristics of concrete. Materials of the XI international scientific - methodological interuniversity seminar "Prospects for the development of new technologies in construction and training of engineering personnel in the Republic of Belarus" (2004)

9. V.S. Mulyarchik, D.Yu. Snezhkov, S.N. Leonovich. Application of a set of nondestructive testing tools for assessing the strength properties of in-situ concrete. In the collection of scientific papers of the international scientific and methodological interuniversity seminar (2005)

10. S.N. Leonovich, D.Yu. Snezhkov, V.S. Mulyarchik, D.M. Markovskiy. Assessment of the stripping strength of concrete when concreting structures under construction conditions using modern non-destructive methods. Bialorusko-Polski Naukowo-Praktyczny Seminarium (2004)

11. S.N. Leonovich, V.S. Mulyarchik, D.Yu. Snezhkov. Applicability of dry contact in ultrasonic testing devices for crack depth control. Materials of the XI international scientific - methodological interuniversity seminar "Prospects for the development of new technologies in construction and training of engineering personnel in the Republic of Belarus (2004) 